\title{
Commentary
}

\section{Musings from the Tribbles Research and Innovation Network}

\author{
Miriam Ruiz-Cantos, Claire E. Hutchison and Carol C. Shoulders *
}

Citation: Ruiz-Cantos, M.; Hutchison, C.E.; Shoulders, C.C. Musings from the Tribbles Research and Innovation Network. Cancers 2021, 13, 4517. https://doi.org/ $10.3390 /$ cancers 13184517

Academic Editor: David Wong

Received: 3 July 2021

Accepted: 4 September 2021

Published: 8 September 2021

Publisher's Note: MDPI stays neutral with regard to jurisdictional claims in published maps and institutional affiliations.

Copyright: (c) 2021 by the authors. Licensee MDPI, Basel, Switzerland. This article is an open access article distributed under the terms and conditions of the Creative Commons Attribution (CC BY) license (https:/ / creativecommons.org/licenses/by/ $4.0 /)$.
Centre for Endocrinology, William Harvey Research Institute, Queen Mary University of London, Charterhouse Square, London EC1M 6BQ 1, UK; m.ruizcantos@qmul.ac.uk (M.R.-C.); c.hutchison@qmul.ac.uk (C.E.H.)

* Correspondence: c.shoulders@qmul.ac.uk

Simple Summary: The Tribbles Research and Innovation Network (TRAIN) was developed in the context of the medical need to understand the contribution that Tribbles (TRIB) proteins make in regulating processes governing the physiological functioning of macrophages and other immune cells, adipocytes and prostate epithelial cells in immuno-metabolic disease (such as obesity) and several cancers. To summarize, TRAIN provided a cohort of $\mathrm{PhD}$ students with a unique opportunity to undertake multidisciplinary research aimed at uncovering the cell-specific mechanisms by which TRIBs exert control over immuno-metabolism and impact on prostate cancer progression. The associated training programme was enhanced by contributions from the TRIB community. This review highlights the science that motivated the establishment of TRAIN, including the discovery of how the TRIB1 protein enables the marking of the transcription factor $\mathrm{C} / \mathrm{EBP} \alpha$ for degradation, and regulatory mechanisms underlying cell-specific TRIB expression. It briefly reflects on the type of TRAIN-associated tools developed for future TRIB research.

Abstract: This commentary integrates historical and modern findings that underpin our understanding of the cell-specific functions of the Tribbles (TRIB) proteins that bear on tumorigenesis. We touch on the initial discovery of roles played by mammalian TRIB proteins in a diverse range of cell-types and pathologies, for example, TRIB1 in regulatory T-cells, TRIB2 in acute myeloid leukaemia and TRIB3 in gliomas; the origins and diversity of TRIB1 transcripts; microRNA-mediated (miRNA) regulation of TRIB1 transcript decay and translation; the substantial conformational changes that ensue on binding of TRIB1 to the transcription factor $C / E B P \alpha$; and the unique pocket formed by TRIB1 to sequester its C-terminal motif bearing a binding site for the E3 ubiquitin ligase COP1. Unashamedly, the narrative is relayed through the perspective of the Tribbles Research and Innovation Network, and its establishment, progress and future ambitions: the growth of TRIB and COP1 research to hasten discovery of their cell-specific contributions to health and obesity-related cancers.

Keywords: gene annotation; transcription; translation; GTEx

\section{Introduction}

On reflection, my group's interest in the TRIB proteins goes back some 12 years. Then, our question was quite simple and primarily motivated by the observation that variants at the TRIB1 locus significantly increased an individual's risk of developing high blood cholesterol and triglyceride levels, and coronary heart disease [1]. Today, as our appreciation and understanding of the work of others has increased, including in the field of cancer, the questions have proliferated and our fascination with this family of pseudokinases has grown. Here, we acknowledge some of the TRIB-research and people that have made it so and refer readers to some excellent review articles [2-6] that are interesting but tangential to the central theme of this commentary: why dissecting the cell-specific functions of TRIB isoforms could help cut through the biological complexities of obesity-related cancers. A particular focus, on TRIB1 genomics, helps showcase the plethora of public resources now available for studying gene expression, while the inclusion 
of the reported TRIB1 protein structures highlights how the central kinase-like domain of the mammalian TRIB proteins may bind a specific yet diverse range of proteins. Notably, the structures also provide insights into how these pseudokinases bind the E3 ubiquitin ligase COP1 via a C-terminal motif to promote proteasomal-mediated degradation of TRIBcaptured substrates. Additionally, we reflect on recent scientific advances and anticipated future developments that could shape the TRIB-research community, viewed through the prism of our (past) membership of the Tribbles Research And Innovation Network (i.e., TRAIN), the members of which are included in the Acknowledgement section of this commentary.

\section{Establishment of TRAIN}

In retrospect, it is clear that persistence and several pivotal events created TRAIN, the brainchild of Professor Endre Kiss-Toth. This persistence involved re-drafting a research and training programme with three main ambitions at its heart. First, to develop and share research tools for studying the complexities of the cell-specific activities of TRIB proteins in common potentially obesity-related diseases, including prostate [7] and breast [8] cancer. Second, to establish strong and sustainable collaborations embodying a broad knowledge base (and appropriate skill sets) that would underpin the interrogation of the growing list of suggested roles of TRIB isoforms in relation to immuno-metabolic disease and malignancy. Third, to provide a multi-disciplinary and inter-sectorial training programme to create a new generation of scientists with a strong springboard to take forward a 'holistic', integrated approach to developing TRIB-targeting therapeutics, including the design of small molecules that selectively modulate physical contacts between the central kinase-like domain of TRIB proteins with a specific protein or subset of proteins.

Arguably, the most direct evidence that the mammalian TRIB proteins might regulate cell-specific processes driving, or indeed suppressing, malignancy came from studies on flies and frogs. For example, genetic screens of Drosophila mutants clearly revealed that its single Tribbles gene (Trbl) regulates many steps in cell proliferation and migration [9], including those required for embryonic [10] and neural [11] development, bristle formation [12] and oogenesis [13]. Moreover, it was well-established that Trbl works by regulating the turnover of key proteins in a cell-specific manner, for example, in cells that form the mesoderm anlage, Trbl degrades the mitotic activator String/CDC25, delaying their cell-division until gastrulation is complete [9], whereas in border cells, which migrate to the anterior end of the oocyte to form a shell-structure through which sperm can enter, Trbl degrades Slbo [14], a key transcription factor promoting border cell migration $[15,16]$.

Four discoveries hinting at the potential cell-specific roles of mammalian TRIB proteins in regulating a diverse range of cell signaling activities, and the ensuing collaborations arising from them, were pivotal in inspiring and creating the TRAIN. One, made by Professor Guillermo Velasco, identified strong association between TRIB3 expression and apoptosis in tumour cells [17]. In brief, Guillermo's story started in the (and not a) cannabinoid field when his then-PhD student Arkaitz Carracedo analysed the transcriptomes of two subclones of glioma cells that displayed different sensitivities to $\Delta^{9}$-tetrahydrocannabinol (THC)-induced apoptosis. In the sensitive cell line, THC induced TRIB3 expression, while in the THC-resistant cell line, enforced TRIB3 expression rescued sensitivity to THCinduced apoptosis. Guillermo's group, in collaboration with Endre, then extended the in vitro phenomenon to an in vivo system by showing that RasV ${ }^{12} / \mathrm{E} 1 \mathrm{~A}-$-Trib3-deficient murine tumour xenografts were also resistant to THC-induced autophagy-mediated cell death [18]. Their next advance, demonstrating that TRIB3-induction by THC inhibited the AKT /mTORC1 axis, corroborated earlier evidence that TRIB3 was likely to influence multiple metabolic processes, and vice versa. In fact, the first-ever sighting of TRIB3 came from a gene expression study that showed that fld2 (i.e., Trib3) RNA was markedly raised in the livers of suckling Lpin1-deficient mice who had fatty liver, plus abnormalities of lipid and glucose metabolism, as a secondary manifestation of impaired adipose tissue development $[19,20]$. Similarly, Trib3 RNA was discovered to be elevated in immortalised 
brown pre-adipocytes prepared from insulin receptor substrate-1 gene knock-out mice [21], characterised by a mild-to-moderate post-receptor insulin resistance phenotype, resembling that of non-insulin-dependent diabetes mellitus at the prediabetes stage.

Another aha moment was the discovery that TRIB3 binds acetyl-coenzyme A carboxylase (ACC) and the E3 ubiquitin ligase COP1 [22], which two years earlier had been shown to be a critical negative regulator of the tumour suppressor protein p53 [23]. In particular, Montminy and colleagues [22] demonstrated that full-length TRIB3 bound both ACC and COP1, whereas a truncated TRIB3 protein lacking the C-terminal 40 amino acid residues could only bind ACC. Compelling data from Karen Keeshan and Warren Pear [24] also revealed that TRIB2 contains separate binding sites for COP1 and its protein substrate, CCAAT/enhancer protein- $\alpha$, and that deletion of the COP1 binding site abrogated TRIB2's ability to degrade this transcription factor, block granulocytic differentiation and induce acute myelogenous leukaemia. In short, and more on this later, a common theme was emerging: TRIB proteins affect multiple cellular functions by binding a wide-range of proteins, including some that they recruit for COP1 to mark for degradation.

The third TRAIN-shaping discovery emerged from a high-throughput screening program designed to identify protein sequences mediating cytokine responses [25], the result of which could so easily have been disregarded. Thus, in outline, when Endre transfected cells with a library of cDNA sequences and assayed their ability to regulate the human IL-8 promoter, he found one that suppressed IL- 8 activity despite it having no open reading frame. It turned out that this unusual IL-8-suppressing construct contained a portion of the $3^{\prime}$ UTR of TRIB1. Pursuing its mechanism of action, Endre then established that the UTR fragment increased endogenous TRIB1 RNA levels in the transfected cells $>10$-fold and, to cut a long story short, repressed $I L-8$ promotor activity by suppressing the activation of the Jun kinase AP-1, the putative transforming gene of avian sarcoma virus 17 . Thus, he sought, and found, evidence that TRIB1 binds via its central kinase-like domain to specific mitogen-activated protein kinase (MAPK) and proposed that mammalian TRIB proteins may, by binding to MAPK, control MAPK activation and, therefore, a cell's response to a diverse range of stimuli, including mitogens and pro-inflammatory cytokines $[25,26]$.

The fourth discovery that inspired the scientific make-up of TRAIN sprang from Professor Sophie Brouard's work on chronic antibody-mediated rejection (AMR) of grafts in kidney transplant recipients [27]. Unexpectedly, Sophie found that TRIB1 RNA levels in their blood were a more specific and sensitive marker of AMR graft-failure than even TRIB1 in their actual renal biopsy samples. Why this might be the case became (a bit) clearer upon finding that TRIB1 is expressed in many peripheral white blood cells, importantly, in the $\mathrm{CD} 4{ }^{+} \mathrm{CD} 25^{\text {high }} \mathrm{CD} 127^{-} \mathrm{Fox}^{+}$subset of regulatory $\mathrm{T}$ cells $[28,29]$ that suppress cellular immunity but at the expense of increasing the risk of cancer [30]. Pondering this result, alongside those produced by others in the field [31,32], had two consequences: appreciation of the enormity of the task that lay ahead in unravelling the isoform- and cell-specific pathogenic versus protective functions of TRIBs in circulating and tissue-resident immune cells, as well as in tumour and metabolic cells; and of the fact that progress on these fronts would be stimulated through a collaborative effort and establishment of a strong Tribbles community focused on this question. TRAIN was conceived, and its progress nurtured by the wider TRIB community, including Professors Robert Bauer, Leonard Dobens, Patrick Eyers, Zhuowei Hu, Wolfgang Link, Karen Keeshan, Peter Mace and Warren Pear.

\section{Tissue- and Cell-Specific Expression of TRIB Family Members}

Mammalian TRIB1 and TRIB2 transcripts were first identified in the thyroid gland [33,34], where TRIB1 has a relatively high abundance (Figure 1). TRIB3, by contrast, was found to be relatively highly expressed in the liver [35], as judged by a Northern blot analysis. That said, it is also apparent from inspecting the Gene-Tissue Expression (GTEx) project data that TRIB1-3 RNA levels exhibit a high degree of inter-person variability in many tissues [36], underlining the value of genome-wide RNA studies in large cohorts to obtain a more objective view of relative isoform-specific TRIB transcript numbers. In the GTEx 
survey of liver samples, for example, the median number of TRIB1 transcripts per million (TPM) is 34.61, compared to TPMs of 22.1 and 59 for the 25th and 75th percentile points (Figure 1). Moreover, eighteen samples contained well in excess of 100 TPM. Similarly, in lung, there is a 2.4- and 2.7-fold difference between the 25th and 75th percentiles values for TRIB1 and TRIB3 RNA contents, respectively, compared to just a 1.5-fold difference for TRIB2 RNA. It is also notable that there is a relatively tight distribution of RFWD2 (encodes COP1) RNA levels in many bodily tissues, although in the liver there is a 1.8-fold difference between the 25th (7.2 TPM) and 75th (12.7 TPM) percentile values.
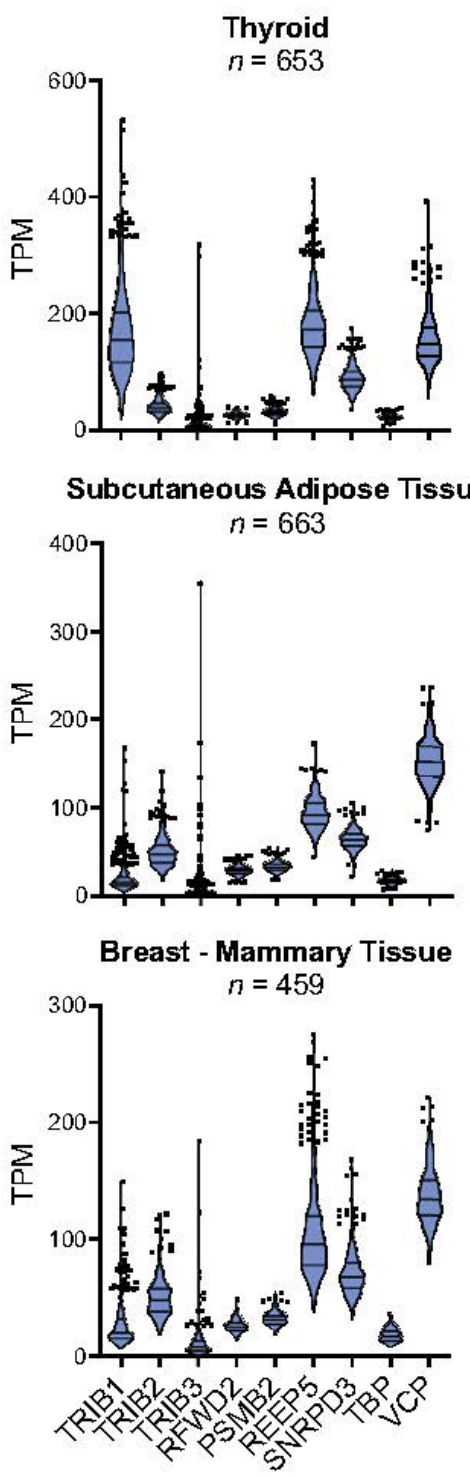

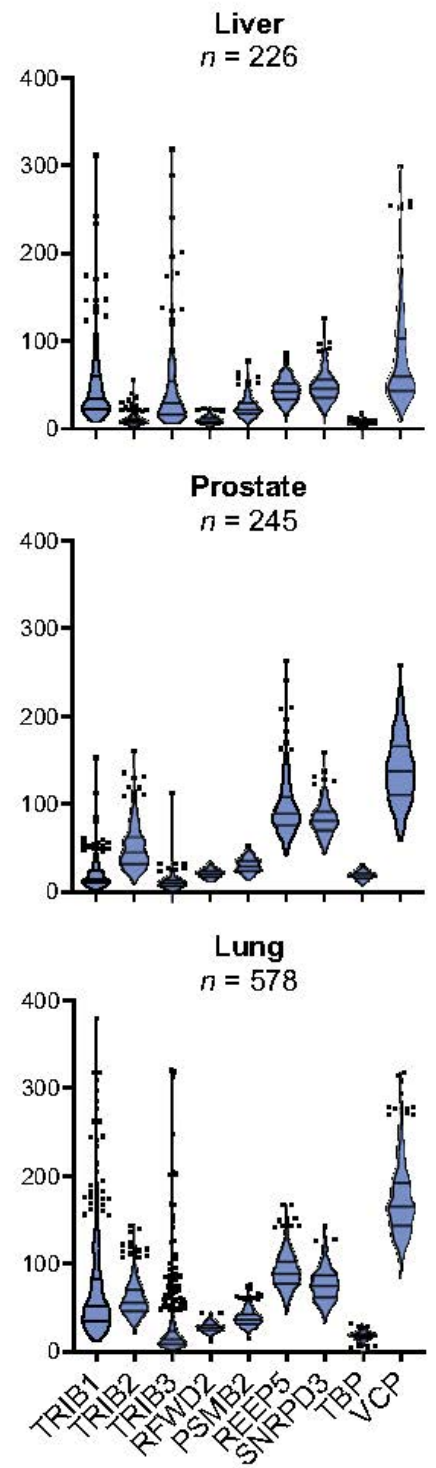

Figure 1. Violin plots of RNA-sequencing data from GTEx consortium (v8) [37] in a selection of tissues. Horizontal lines indicate median, 25th and 75th percentile values; black dots represent values $>1.5 \times$ the interquartile range below or above these values. $\mathrm{TPM}=$ transcripts per million. PSMB2 = proteasome subunit beta 2; REEP5 = receptor accessory protein 5; SNRPD3 = small nuclear ribonucleoprotein D3; TBP = TATA-box binding protein; $\mathrm{VCP}=$ valosin-containing protein .

It would be tempting to ignore the relatively high inter-personal variability in tissue TRIB RNA levels due to the acknowledged technical limitations of the GTEx project [38-41], for example, differences in the cell compositions of tissues. However, to do so seems premature until we know more about the biology regulating TRIB expression in specific celltypes, and in co-culture systems that recapitulate the cellular and physiological complexities of tissues. Thus, we envisage that these data will identify specific confounding variables 
affecting TRIB expression, including in specific cell-types, and that these confounders will contribute to the observed variances of TRIB RNA levels in the GTEx tissues. It is also highly probable that genetic variants add to this variance by affecting TRIB transcript production and decay, and that many such variants will be discovered in further analyses that correct for the effects of non-genetic factors on TRIB expression.

Homing in on the study of TRIB expression in specific cell-types, we are especially drawn to the painstaking analysis of hemopoietic cells undertaken by Keeshan and colleagues [42]. First, the analysis itself, which nicely shows, through the collation of publicly available data, the expression profiles of TRIB1-3 in murine and human hemopoietic stem, progenitor and mature cells, including in those of leukemic patients. Second, the biological inferences made by Karen from these analyses, for example, changes in TRIB1 expression may contribute to the progression of HOX9-induced myeloid leukaemia, as subsequently shown [43], and TRIB3 may play a novel role in stem cell quiescence.

\section{Genomic and Structural Data: Insights into TRIB Expression}

The past five years have witnessed remarkable progress in understanding the contribution of the myriad of nuclear and cytoplasmic processes regulating transcript diversity and abundance [44-48]. Particularly helpful resources for this type of analysis include RNA-sequencing (RNA-seq) and Cap analysis of gene expression (CAGE) data [49] generated by the Encyclopaedia of DNA Elements (ENCODE) and Functional Annotation of Mammalian Genome consortiums. We have used CAGE to map the transcription start sites of TRIB1 and have been reminded that annotated transcripts in the genome browsers may represent degradation products rather than a bona fide transcript with the usual features initiating translation: the 7-methyl-guanosine cap at the $5^{\prime}$ end and a $3^{\prime}$ polyadenylated (poly A) tail. To demonstrate this point, we compare and contrast genomic data for two TRIB1 transcripts: TRIB1-201, designated on the Ensembl browser, as the principal species, and TRIB1-203 as a product of alternative splicing (Figure 2). The latter, which may derive from spurious transcription [50], lacks exon 1 sequences, has a short $3^{\prime}$ UTR and no poly A tail, and is predicted by Ensembl to initiate translation from Met167.

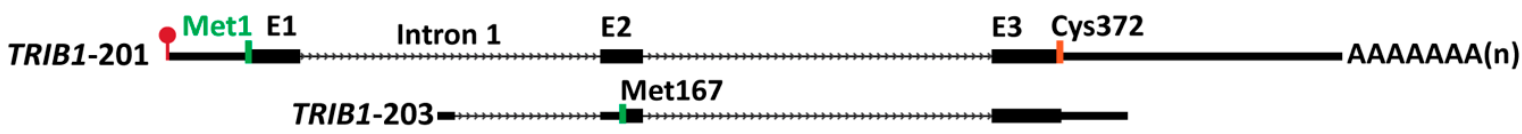

Figure 2. Example of annotated alternatively spliced TRIB transcript. Adapted from Ensembl and drawn to scale. N.B. Arrowed lines representing intronic sequences, which are removed from precursor TRIB1-201 (ENST00000311922) and TRIB1-203 (ENST00000520847) transcripts during splicing. Black rectangles and lines represent coding and non-coding sequences, respectively. Red dot and poly A tail highlight that the TRIB-201 transcript is capped and polyadenylated. Met1 and Met167 indicate assumed translation initiation codons. $\mathrm{E}=$ exon.

From conventional cDNA studies and CAGE analyses, we infer that TRIB1 transcription is predominantly initiated from multiple sites centred on a $220 \mathrm{bp}$ stretch of DNA $\sim 550$ upstream of the canonical translation initiation codon of TRIB1 in a cell-specific manner (Figure 3). Moreover, we infer that such transcripts are $5^{\prime}$-capped and exported to the cytoplasm (Figure 3) attached to both their cap-binding complex and exon-junction complexes (EJCs) assembled on exon-termini joined by splicing. Within the cytoplasm, the cap-binding complex is replaced by the eukaryotic translation initiation factor, thereby promoting recruitment of the $43 \mathrm{~S}$ ribosomal pre-initiation complex to the $\mathrm{m} 7-\mathrm{G}$ Cap, whose main role is to locate and pin the translation initiation codon to further components of the translation machinery. For some TRIB1-201 transcripts, the pre-initiation complex would need to scan (in $5^{\prime}$ to $3^{\prime}$ direction) at least 927 nucleotides of the capped transcript before it finds the start codon (Figure 3), enabling TRIB1 protein synthesis to proceed. 


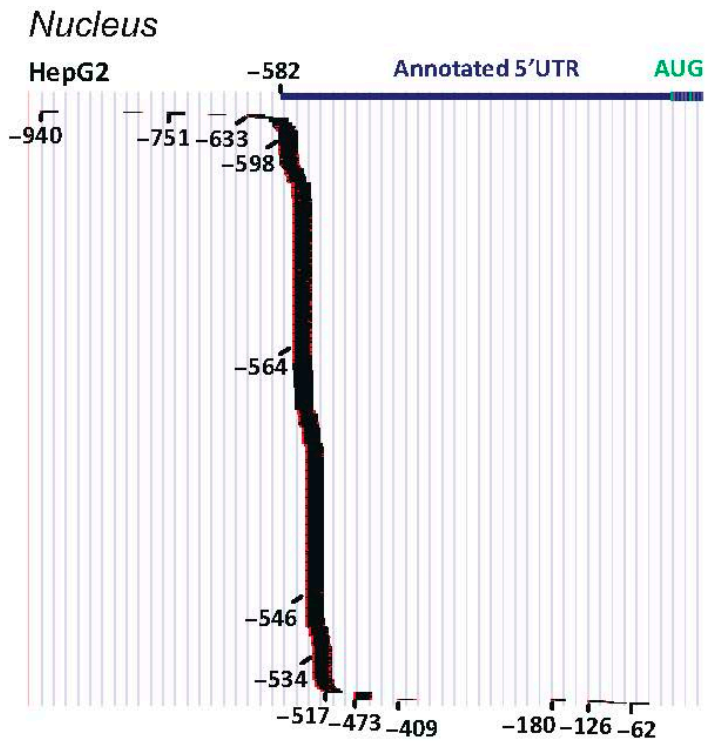

Nucleus

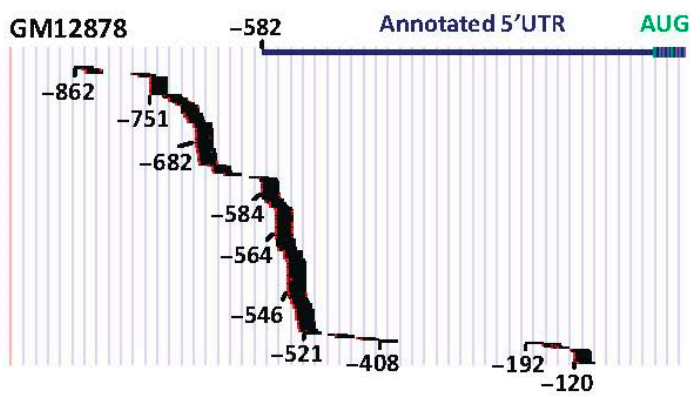

\section{Cytoplasm}

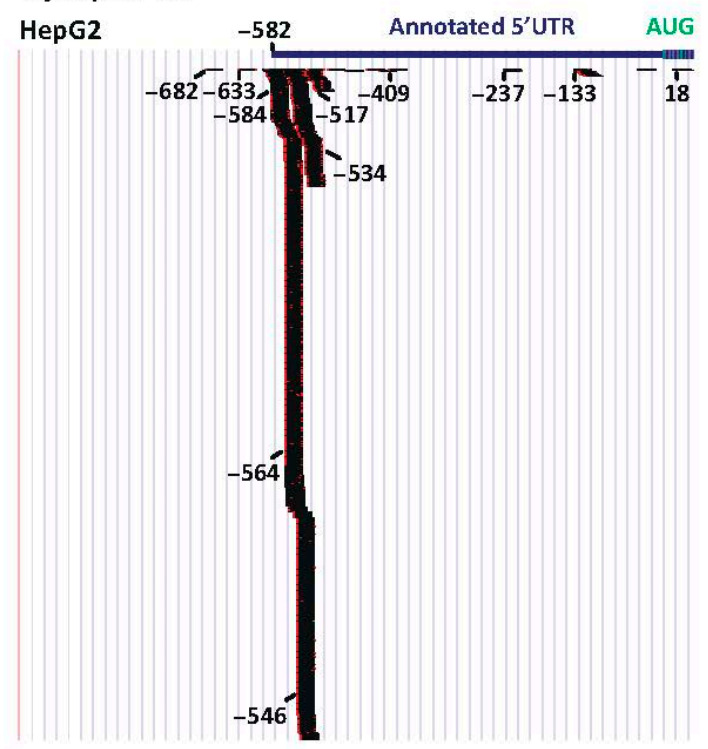

Cytoplasm

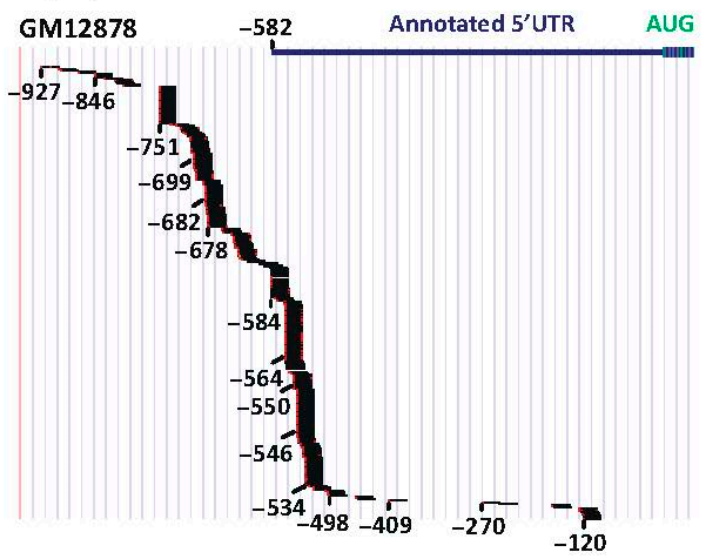

Figure 3. Initiation of TRIB1 transcription from multiple sites within a core promoter. Visualisation of CAGE tags in the promoter region of TRIB1. Blue bar represents Ensembl-annotated TRIB15'UTR. Numbering, in base pairs, is from the translation initiation codon (AUG, green). Each horizontal black bar represents a capped transcript: $n=1435$ and 429 (nucleus) and 1670 and 534 (cytoplasm) in the 1kbp upstream of the translation initiation codon AUG in HepG2 and EpsteinBarr-virus-transformed lymphoblastoid cell line GM12878, respectively. Annotated sequence from the GRCh37/hg19 Assembly, drawn to scale.

Conventional cDNA cloning and sequencing methodologies and RNA-seq data (Figure 4A) now clearly show that the TRIB1-203 transcript reflects splicing at a cryptic donor splice-site deep within intron 1 (Figures 2 and 4A). A re-appraisal of the proteincoding status and, thus, potential significance of this alternatively-spliced transcript is thus urgently needed to understand whether its expression might contribute, for example, to a cell's response to a diverse range of stimuli, including mitogens and pro-inflammatory cytokines [25,26]. Currently, standard genome annotation methods indicate that TRIB1-203 uses a translation initiation codon within exon 2 (Met167) to generate a 206 amino acid protein (Figure 2). However, it seems implausible from structural data that this N-terminally truncated protein could adequately control ubiquitination of its target protein substrates (Figure 4B). As Peter Mace so eloquently explained at the second international symposium on Tribbles and Diseases [51], the $\alpha C$-helix (amino acids 127-140) and $\beta 4$ strand (amino acids 146-151) of TRIB1 (Figure 4B) protect it from COP1-mediated ubiquitination and ensuing proteasome-mediated degradation. In brief, these two structural elements sequester the $\mathrm{C}$-terminal COP1-binding motif, preventing it from recruiting COP1. Protein substrates, 
such as C/EBP $\alpha$, bind to a central portion of TRIB1's pseudokinase domain (Figure 4C) and initiate changes that destabilise the COP1-motif binding pocket, thereby freeing the COP1binding peptide to seek out COP1 and ubiquitinate the TRIB1-bound substrate. Hence, the potential regulatory importance of limiting the production of the putative TRIB1-203 geneproduct is that it could bind COP1 unimpeded, initiate self-ubiquitination and degradation of this putative TRIB1 isoform and adversely affect its ability to recruit a wide range of protein substrates to COP1 to facilitate their ubiquitination and subsequent degradation.

A $5^{\prime} \quad$ Intron

tccatgactggggctaagagctgttctgggacaagcatgt

Exon2 agGTGTTTCCCATTAAACACT... ${ }^{3}$

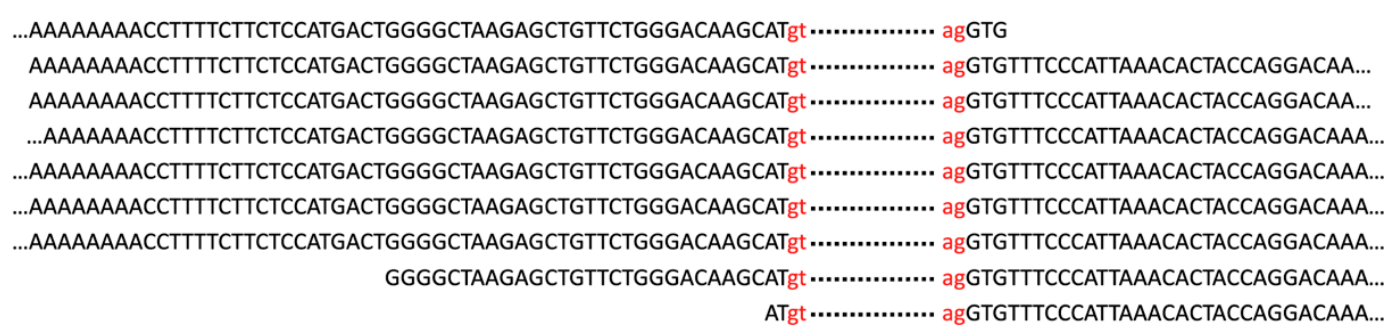

B

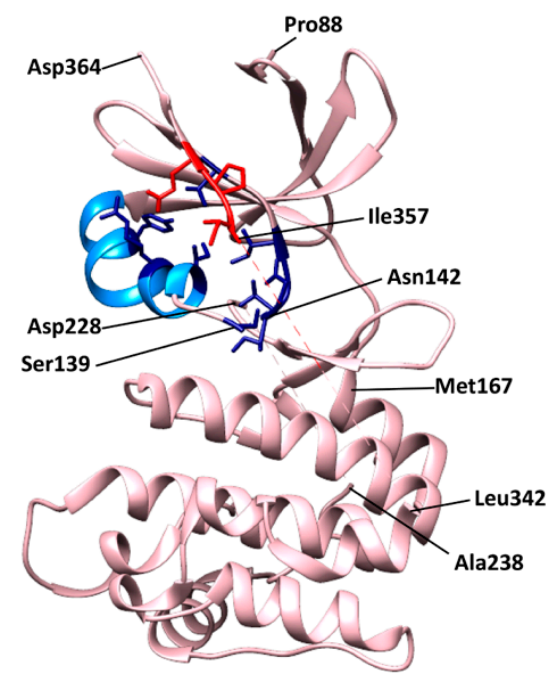

C

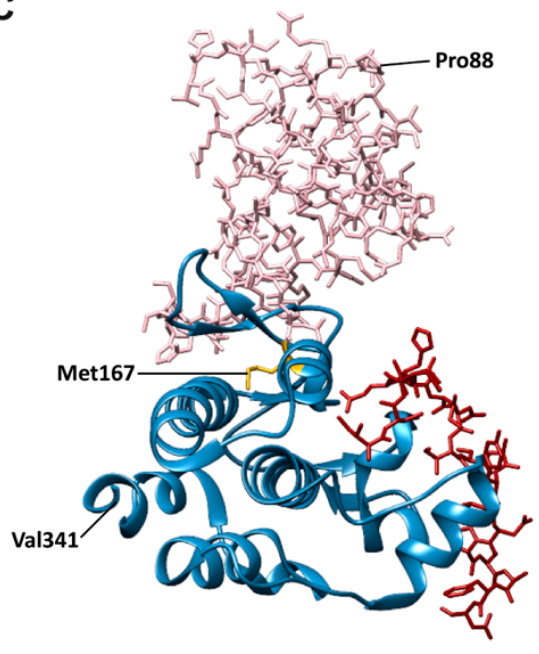

Figure 4. Analysis of putative TRIB1-203 gene-product. (A)TRIB1-203 transcripts detected in whole-cell total RNA extracted from human diencephalon, frontal cortex, occipital and parietal lobe samples. RNA-seq reads, downloaded from ENCODE, aligned against reference genome hg38. Nine TRIB1-203 transcripts were detected in these samples compared to 263 reads crossing the canonical exon 1 and 2 junctions. Nucleotides "gt" and "ag" define the splicing junction represented by the dotted line and are not present in the read sequence. (B) Schematic of structure for amino acids 84-365 of substrate-free TRIB1 (5CEM) [52]. Selected residues in $\alpha$ C-helix (depicted in blue) and $\beta 4$-strand forming the COP1-binding peptide (red) binding pocket are depicted as sticks. Pink dotted lines: no electron density for amino acids 229-237 and 343-356. (C) Structure for amino acids 53-75 of C/EBP $\alpha$ (brown) bound to N- and C-terminally truncated TRIB1 [53]. Blue ribbons represent structures predicted to be encoded by the TRIB1-203 transcript.

The finding that spuriously transcribed transcripts are degraded shortly after their transcription to limit their accumulation and potential for translation [50] may explain, at least in part, the low abundance of the TRIB1-203 transcript in a range of tissues (Figure 4A) and cell lines. As illustrated in Figure 5A, we find that capped TRIB1-203 transcripts are a very minor TRIB1 species in the nucleus of ten commonly used cell lines, with RNA-seq data returning read profiles that one would expect to see for cleaved product (compare Figure 5B with Figure 5C). CAGE data further show that capped TRIB1-203 transcripts are rare in the cytoplasm (i.e., one or none per cell line), consistent with RNA-seq estimates of TRIB1-203 mRNA abundance in these cell lines (Figure 5D). Less clear is whether 
cytoplasmic RNA decay prevents cap-mediated translation of TRIB1-203 transcripts and, in particular, what role EJC-dependent nonsense mediated degradation $[54,55]$ might play in determining the abundance and translation capacity of this and other alternatively spliced TRIB transcripts, including in malignancy.



Distance from Canonical Splicing Site

B $5^{\prime} \quad$ Intron 1
...cttttcttctccatgactggggctaagagctgttctgggacaagcatgt $5^{\prime} \quad$ Intron 1
...cttttcttctccatgactggggctaagagctgttctgggacaagcatgt

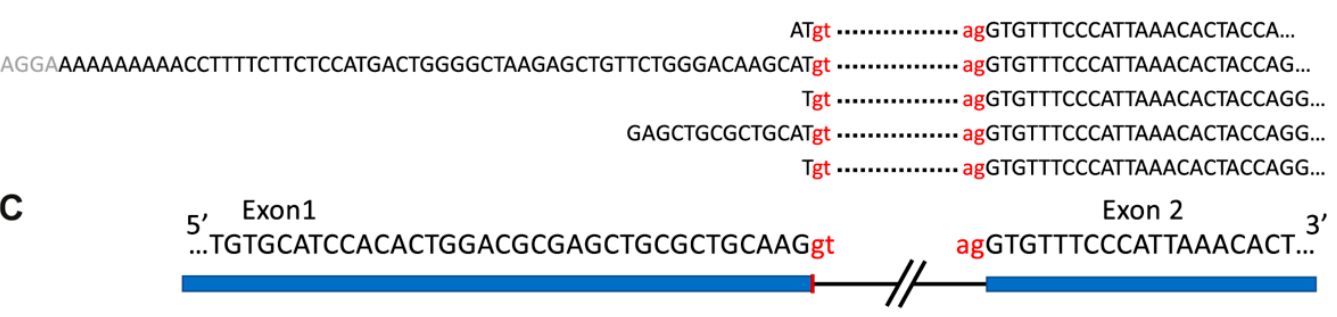
AGCTGCGCTGCAAGgt ................. agGTGTTTCCCATTAAACACTACCAGG... ....GGCGAGCATGTGTCCCGGGCGCTGTGCATCCACACTGGACGCGAGCTGCGCTGCAAGgt ………..... agGTGTTTCCCATTAA ...CGCGAGCATGTGTCCCGGGCGCTGTGCATCCACACTGGACGCGAGCTGCGCTGCAAGgt ……......... agGTGTTTCCCAT TGGACGCGAGCTGCGCTGCAAGgt ………..... agGTGTTTCCCATTAAACACTACCAGG... CGCTGTGCATCCACACTGGACGCGAGCTGCGCTGCAAGgt …............ agGTGTTTCCCATTAAACACTACCAGG... CGAGCTGCGCTGCAAGgt ……......... agGTGTTTCCCATTAAACACTACCAGG... GAGCTGCGCTGCAAGgt …............. agGTGTTTCCCATTAAACACTACCAGG... ATGCGCTGCAAGgt …............. agGTGTTTCCCATTAAACACTACCAGG... GCTGCGCTGCAAGgt ….............. agGTGTTTCCCATTAAACACTACCAGG... cCCGGGCGCTGTGCATCCACACTGGACGCAAGCTGCGCTGCAAGgt ……........ agGTGTTTCCCATTAAACACTACCAGG...

D

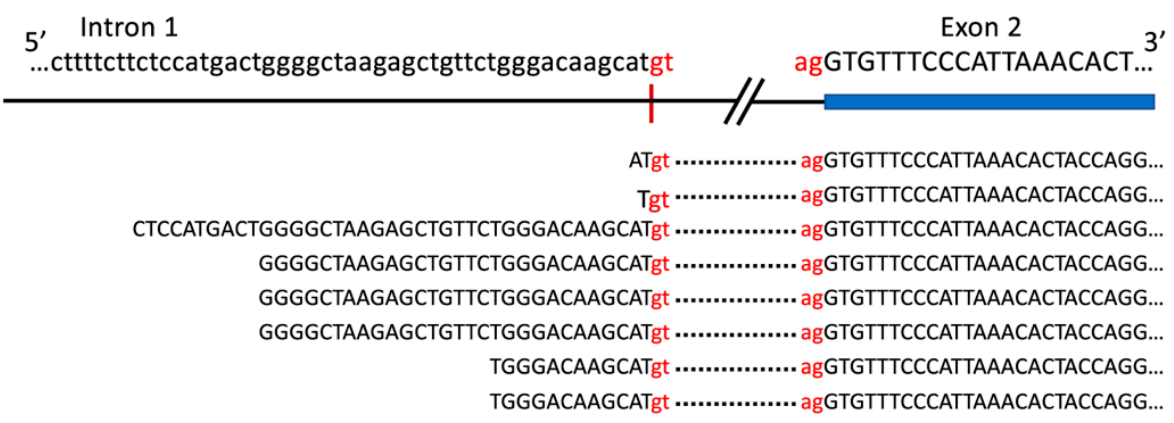

Figure 5. Distinguishing features of nuclear and cytoplasmic TRIB1-203 transcripts. (A) Capped transcripts in nuclear, poly A-enriched RNA in nine of ten examined ENCODE cell lines. Numbering ( $x$-axis), nucleotides from beginning of intron 1. No CAGE tags were identified in the SK-N-SH cell line established from a bone marrow metastasis from a young female with neuroblastoma. CAGE tags (number, $y$-axis) mapping upstream of nucleotide 866 in intron 1 represent potential transcription 
start sites for the TRIB1-203 transcript. Corresponding number of (nuclear) CAGE tags mapping to the core promoter of TRIB1-201 range from 253 in the K562 cell line derived from an adult chronic myelogenous leukaemia patient in blast crisis to 2955 in the human lung fibroblast cell line IMR90. (B) RNA-seq reads for TRIB1-203 transcripts $(n=6$ in total) detected in nuclear, poly A-enriched RNA of three (two replicates of each) ENCODE cell lines: HeLa, HUVEC and IMR90. N.B. only one read from each replicate is shown. (C) The first ten RNA-seq reads $(n=375)$ represent TRIB1-201 transcripts in nuclear, poly A-enriched RNA extracted from HepG2 cells. (D) RNA-seq reads for TRIB1-203 transcripts $(n=8$ in total) detected in cytoplasmic, poly A-enriched RNA of the four specified ENCODE cell lines. Corresponding numbers for the TRIB1-201 transcript range from 86 for the K562 cell line to 1694 for the carcinomic human alveolar basal epithelial cell line.

As highlighted by the research of Niespolo and colleagues [56] on behalf of TRAIN, we now know of at least two microRNAs (miRNAs) that, through their binding to the $3^{\prime} \mathrm{UTR}$ of TRIB1, increase IL-8 expression. However, a full description (and even understanding) of how this class of RNAs regulate TRIB1 protein levels will require significant advances in miRNA technologies. These include the development of robust high-throughput assays to quantify the individual, combined and cooperative effects of 1000+ candidate miRNAs (Figure 6) on TRIB1 transcript decay and translation, as well as software to compare expression values under basal and induced conditions. From data produced so far, it seems entirely feasible that TRIB1-targeting miRNAs have medium-to-large effect-sizes on TRIB1-transcript levels and translatability, and that their expression is regulated by both genetic and cell-specific signals. Moreover, as the number of TRIB1-binding miRNAs in a cell increase, this could have a more direct and larger impact on TRIB1-mediated functions than a cis-acting TRIB1 disease-risk variant identified in large population type studies.



Figure 6. Cell-specific microRNA targeting of capped, polyadenylated TRIB1 transcripts. Newly-synthesised, capped, polyadenylated TRIB1 transcripts are subjected to microRNA (miRNA)-mediated de-adenylation and translational repression. Newly exported TRIB1 transcript (centre cell) fate will vary on cell-type, physiological cues and miRNA compliment (coloured cells). The relatively long ( 2000 nucleotides) 3' untranslated region of the TRIB1-201 transcript contains potential binding sites for 1237 different miRNA [56]. Binding of miRNAs to closely-spaced sites (2 o'clock position) may facilitate cooperative behaviour leading to more de-adenylation and translational repression of TRIB1-201 transcripts than that achieved through combinational binding of miRNAs to target sites separated by $>\sim 60$ nucleotides [57] (4 o'clock position). 


\section{Growth of TRIB (and COP1) Research}

There is no doubt that developing a website of available TRIB-research tools will help the TRIB community, but for now we are confined to just highlighting those in the TRAIN tool-box, some of which can be accessed via contact with a TRAIN consortium member (Acknowledgements). An important early decision was to use a standard set of prostate cancer cell lines (Table 1) in gene expression and cell-biological analyses, and in xenograft models of human prostate cancer. Notably, TRIB1 protein levels are relatively high in the PC3 cell line, whereas COP1 is undetectable, raising the question whether COP1 under specific stimulatory conditions may mark TRIB1 for proteasome-mediated degradation. Increasing TRIB1 expression in these PC 3 cells has been shown to promote tumour growth [58], whereas increasing TRIB1 in DU145 cells did not [59]. Consequently, we keenly await proteomic analyses of the TRIB-interactome in the COP1-less PC 3 cells, as well as structural studies that define the effects of TRIB1-captured protein substrates on the release of its sequestered C-terminal COP1-binding motif. Once these analyses have been undertaken, we may be better placed to understand the relative balance of TRIB's different functions: providing a scaffold for signalling molecules to assemble versus acting as a COP1 recruiting sergeant for accelerating protein degradation. We are also very curious to understand under what circumstances TRIB1 (and potentially TRIB2, TRIB3) promotes nuclear COP1 retention [60], and to what effect?

Table 1. Characteristics of prostate cancer cell lines used by TRAIN consortium.

\begin{tabular}{|c|c|c|c|c|}
\hline Cell Line & Characteristics & TRIB1 Protein Levels 1 & COP1 Protein & Publications \\
\hline PC3 & $\begin{array}{l}\text { PTEN }^{-} \text {[61] } \\
\text { Androgen-independent [62] } \\
\text { Bone metastasis }\end{array}$ & High & $\begin{array}{c}\text { Genome rearrangement } \\
\text { undetectable protein }[63,64]\end{array}$ & $\begin{array}{l}\text { Shahrouzi et al., } 2020 \text { [59] } \\
\text { Niespolo et al., } 2020 \text { [56] }\end{array}$ \\
\hline DU145 & $\begin{array}{l}\text { PTEN }^{+}[65] \\
\text { Androgen-independent [66] } \\
\text { Brain metastasis }\end{array}$ & NA & Yes $[63,67]$ & Shahrouzi et al., 2020 [59] \\
\hline LNCaP & $\begin{array}{l}\text { PTEN }^{-} \text {[61] } \\
\text { Androgen-sensitive [62] } \\
\text { Lymph node metastasis }\end{array}$ & Low & Yes $[63,64,67]$ & Niespolo et al., 2020 [56] \\
\hline 22Rv1 & $\begin{array}{c}\text { PTEN }^{+}[68,69] \\
\text { Androgen-sensitive [62] } \\
\text { Prostate }\end{array}$ & Low & Yes, based on RNA ${ }^{2}$ & \\
\hline
\end{tabular}

1 TRIB1 protein levels defined in a comparative manner based on experiments from Mashimaet al. [58]; NA = Not Available: not included in comparative analysis. ${ }^{2}$ Data from Cancer Cell Line Encyclopaedia.

Returning to the TRAIN tool-box, this includes a series of scripts to interrogate and visualise genomic data, plasmid and viral constructs, and murine models to study the physiological roles of cell-specific TRIB1 and TRIB3 expression, for example, in myeloid cells [70], prostate-specific Pten-deficient mice [59] and Tregs (Trib1 ${ }^{\mathrm{KO}}$, richard.danger@univ-nantes.fr; sophie.brouard@univ-nantes.fr). Finally, we would like to thank the wider TRIB community for their contribution to student TRAIN training events and bi-annual international TRIB conferences. Reflecting on the next TRIB conference, planned for the spring of 2023 under the auspices of Professors Robert Bauer, Leonard Dobens and Warren Pear, we look forward to meeting up in person and finding out how the collaborative approaches adopted by the TRIB community have accelerated mechanistic understanding into how each TRIB protein and binding partner contribute mechanistically to tumorigenesis.

\section{Conclusions}

TRIB proteins determine the abundance and subcellular distribution of a diverse range of proteins. An unknown proportion of TRIB-captured proteins are marked for degradation by the E3 ubiquitin ligase COP1, which binds to TRIB proteins via their Cterminal motifs. Importantly, COP1 has also been shown to regulate protein levels in a non-TRIB-mediated process, and there are data to suggest that TRIB1 inhibits nuclear 
export of COP1 once it enters the nucleus. However, data to compare how strongly endogenous TRIB proteins and non-TRIB protein complexes compete for recruitment of COP1 to promote proteasomal-mediated degradation of their captured proteins are lacking. In contrast, and as outlined in this review, publicly available genomic datasets are a valuable resource to better understand mechanisms of cell-specific regulation of mammalian TRIB and COP1 (i.e., RFWD2) expression. Now, we await the results of experimental exploration of how altered TRIB/COP1 expression affects isoform-specific TRIB abundance, subcellular distribution and downstream functions-a pre-requisite for designing a range of TRIB/COP1-therapeutics to ameliorate obesity-related cancers. Regarding drug development, we envisage that the diverse, and potentially opposing, biological activities of TRIB proteins and COP1 may limit their consideration as specific targets, and that a more promising option will be the development of small molecules that suppress/induce TRIB/COP1 binding to a subset of their downstream effectors.

Author Contributions: Writing—original draft preparation, C.C.S.; writing—review and editing, all authors; visualization, M.R.-C. and C.E.H.; supervision, C.C.S.; funding acquisition, C.C.S. All authors have read and agreed to the published version of the manuscript.

Funding: Work on Tribbles by M.R.-C. and C.C.S. has been funded by the European Union's Horizon 2020 Marie Skłodowska-Curie Innovative Training Network, TRAIN (project no. 721532).

Acknowledgments: We thank all contributors to the field of Tribbles research and TRAIN plus Andrew Dean for his critical review of this commentary. TRAIN consortium members: Endre KissToth (TRAIN programme coordinator), Xavier Barril, Sophie Brouard, Arkaitz Carracedo, Richard Danger, Sheila Francis, Stephan Herzig, Eric Kalkhoven, Louise Metherell, Istvan Nagy, Natalia Pellegata, Marcel Scheideler, Carol Shoulders, Silvia Socorro, Ian Sudbery, Guillermo Velasco, Oscar Villacañas, Heather Wilson, Sonia Castillo, Jessica Johnston, Graham Hughes (TRAIN programme manager), Claire Hutchison, Kunzangla Bhutia, Jack Day, Sumeet Desmukh, Yodit Feseha, Dominika Grzesik, Ffion Hammond, Miguel Henandez-Quiles, Rhoda Anane Karikari, Taewoo Kim, Adam Linford, Laura Martinez Campesino, Imogen Morris, Chiara Niespolo, Alba Orea Soufi, Miriam Ruiz Cantos, Juan Salamanca Viloria, Swapna Satam, Parastoo Shahrouzi and Ziyanda Shologu. GTEx project was supported by the Common Fund of the Office of the Director of the National Institutes of Health, and by NCI, NHGRI, NHLBI, NIDA, NIMH, and NINDS.

Conflicts of Interest: The authors declare no conflict of interest.

\section{References}

1. Calandra, S.; Tarugi, P.; Speedy, H.E.; Dean, A.F.; Bertolini, S.; Shoulders, C.C. Mechanisms and genetic determinants regulating sterol absorption, circulating LDL levels, and sterol elimination: Implications for classification and disease risk. J. Lipid Res. 2011, 52, 1885-1926. [CrossRef]

2. Örd, T.; Örd, T. Mammalian Pseudokinase TRIB3 in Normal Physiology and Disease: Charting the Progress in Old and New Avenues. Curr. Protein Pept. Sci. 2017, 18, 819-842. [CrossRef]

3. Dobens, L.; Nauman, C.; Fischer, Z.; Yao, X. Control of Cell Growth and Proliferation by the Tribbles Pseudokinase: Lessons from Drosophila. Cancers 2021, 13, 883. [CrossRef]

4. Jadhav, K.S.; Bauer, R.C. Trouble with Tribbles-1. Arter. Thromb. Vasc. Biol. 2019, 39, 998-1005. [CrossRef]

5. Mayoral-Varo, V.; Jiménez, L.; Link, W. The Critical Role of TRIB2 in Cancer and Therapy Resistance. Cancers 2021, 13, 2701. [CrossRef]

6. Fang, Y.; Zekiy, A.O.; Ghaedrahmati, F.; Timoshin, A.; Farzaneh, M.; Anbiyaiee, A.; Khoshnam, S.E. Tribbles homolog 2 (Trib2), a pseudo serine/threonine kinase in tumorigenesis and stem cell fate decisions. Cell Commun. Signal. 2021, 19, 41. [CrossRef]

7. Pernar, C.H.; Ebot, E.M.; Wilson, K.M.; Mucci, L.A. The Epidemiology of Prostate Cancer. Cold Spring Harb. Perspect. Med. 2018, 8, a030361. [CrossRef]

8. Blücher, C.; Stadler, S.C. Obesity and Breast Cancer: Current Insights on the Role of Fatty Acids and Lipid Metabolism in Promoting Breast Cancer Growth and Progression. Front. Endocrinol. 2017, 8, 293. [CrossRef] [PubMed]

9. Dobens, L.L.; Bouyain, S. Developmental roles of tribbles protein family members. Dev. Dyn. 2012, 241, 1239-1248. [CrossRef] [PubMed]

10. Großhans, J.; Wieschaus, E. A Genetic Link between Morphogenesis and Cell Division during Formation of the Ventral Furrow in Drosophila. Cell 2000, 101, 523-531. [CrossRef]

11. Saka, Y.; Smith, J. A Xenopus tribbles orthologue is required for the progression of mitosis and for development of the nervous system. Dev. Biol. 2004, 273, 210-225. [CrossRef] 
12. Abdelilah-Seyfried, S.; Chan, Y.M.; Zeng, C.; Justice, N.J.; Younger-Shepherd, S.; Sharp, L.E.; Barbel, S.; Meadows, S.A.; Jan, L.Y.; Jan, Y.N. A gain-of-function screen for genes that affect the development of the Drosophila adult external sensory or-gan. Genetics 2000, 155, 733-752. [CrossRef]

13. Mata, J.; Curado, S.; Ephrussi, A.; Rørth, P. Tribbles Coordinates Mitosis and Morphogenesis in Drosophila by Regulating String/CDC25 Proteolysis. Cell 2000, 101, 511-522. [CrossRef]

14. Masoner, V.; Das, R.; Pence, L.; Anand, G.; LaFerriere, H.; Zars, T.; Bouyain, S.; Dobens, L.L. The kinase domain of Drosophila Tribbles is required for turnover of fly C/EBP during cellmigration. Dev. Biol. 2013, 375, 33-44. [CrossRef]

15. Levine, B.; Hackney, J.F.; Bergen, A.; Dobens, L.; Truesdale, A.; Dobens, L. Opposing interactions between Drosophila Cut and the C/EBP encoded by Slow Border Cells direct apical constriction and epithelial invagination. Dev. Biol. 2010, 344, 196-209. [CrossRef]

16. Ogienko, A.A.; Yarinich, L.A.; Fedorova, E.V.; Dorogova, N.V.; Bayborodin, S.I.; Baricheva, E.M.; Pindyurin, A.V. GAGA Regulates Border Cell Migration in Drosophila. Int. J. Mol. Sci. 2020, 21, 7468. [CrossRef]

17. Carracedo, A.; Lorente, M.; Egia, A.; Blázquez, C.; García, S.; Giroux, V.; Malicet, C.; Villuendas, R.; Gironella, M.; González-Feria, L.; et al. The stress-regulated protein p8 mediates cannabinoid-induced apoptosis of tumor cells. Cancer Cell 2006, 9, 301-312. [CrossRef]

18. Salazar, M.; Lorente, M.; García-Taboada, E.; Hernández-Tiedra, S.; Davila, D.; Francis, S.; Guzmán, M.; Kiss-Toth, E.; Velasco, G. The pseudokinase tribbles homologue-3 plays a crucial role in cannabinoid anticancer action. Biochim. et Biophys. Acta (BBA) Mol. Cell Biol. Lipids 2013, 1831, 1573-1578. [CrossRef]

19. Klingenspor, M.; Xu, P.; Cohen, R.D.; Welch, C.; Reue, K. Altered Gene Expression Pattern in the Fatty Liver Dystrophy Mouse Reveals Impaired Insulin-mediated Cytoskeleton Dynamics. J. Biol. Chem. 1999, 274, 23078-23084. [CrossRef]

20. Péterfy, M.; Phan, J.; Xu, P.; Reue, K. Lipodystrophy in the fld mouse results from mutation of a new gene encoding a nuclear protein, lipin. Nat. Genet. 2001, 27, 121-124. [CrossRef]

21. Tseng, Y.-H.; Butte, A.J.; Kokkotou, E.; Yechoor, V.K.; Taniguchi, C.M.; Kriauciunas, K.M.; Cypess, A.M.; Niinobe, M.; Yoshikawa, K.; Patti, M.E.; et al. Prediction of preadipocyte differentiation by gene expression reveals role of insulin receptor substrates and necdin. Nat. Cell Biol. 2005, 7, 601-611. [CrossRef]

22. Qi, L.; Heredia, J.E.; Altarejos, J.Y.; Screaton, R.; Goebel, N.; Niessen, S.; MacLeod, I.X.; Liew, C.W.; Kulkarni, R.N.; Bain, J.R.; et al. TRB3 Links the E3 Ubiquitin Ligase COP1 to Lipid Metabolism. Science 2006, 312, 1763-1766. [CrossRef]

23. Dornan, D.; Wertz, I.; Shimizu, H.; Arnott, D.; Frantz, G.D.; Dowd, P.; Rourke, K.O.; Koeppen, H.; Dixit, V.M. The ubiquitin ligase COP1 is a critical negative regulator of p53. Nature 2004, 429, 86-92. [CrossRef]

24. Keeshan, K.; Bailis, W.; Dedhia, P.H.; Vega, M.E.; Shestova, O.; Xu, L.; Toscano, K.; Uljon, S.N.; Blacklow, S.C.; Pear, W.S. Transformation by Tribbles homolog 2 (Trib2) requires both the Trib2 kinase domain and COP1 binding. Blood 2010, 116, 4948-4957. [CrossRef]

25. Kiss-Toth, E.; Bagstaff, S.M.; Sung, H.Y.; Jozsa, V.; Dempsey, C.; Caunt, J.C.; Oxley, K.M.; Wyllie, D.H.; Polgar, T.; Harte, M.; et al. Human Tribbles, a Protein Family Controlling Mitogen-activated Protein Kinase Cascades. J. Biol. Chem. 2004, 279 , 42703-42708. [CrossRef]

26. Sung, H.Y.; Guan, H.; Czibula, A.; King, A.R.; Eder, K.; Heath, E.; Suvarna, S.K.; Dower, S.K.; Wilson, A.G.; Francis, S.; et al. Human Tribbles-1 Controls Proliferation and Chemotaxis of Smooth Muscle Cells via MAPK Signaling Pathways. J. Biol. Chem. 2007, 282, 18379-18387. [CrossRef]

27. Ashton-Chess, J.; Giral, M.; Mengel, M.; Renaudin, K.; Foucher, Y.; Gwinner, W.; Braud, C.; Dugast, E.; Quillard, T.; Thebault, P.; et al. Tribbles-1 as a Novel Biomarker of Chronic Antibody-Mediated Rejection. J. Am. Soc. Nephrol. 2008, 19, 1116-1127. [CrossRef]

28. Alvarez, C.M.; Opelz, G.; Garcia, L.F.; Süsal, C. Expression of Regulatory T-Cell-Related Molecule Genes and Clinical Outcome in Kidney Transplant Recipients. Transplantation 2009, 87, 857-863. [CrossRef]

29. Dugast, E.; Kiss-Toth, E.; Docherty, L.; Danger, R.; Chesneau, M.; Pichard, V.; Judor, J.-P.; Pettré, S.; Conchon, S.; Soulillou, J.-P.; et al. Identification of Tribbles-1 as a Novel Binding Partner of Foxp3 in Regulatory T Cells. J. Biol. Chem. 2013, 288, 10051-10060. [CrossRef]

30. Mockler, M.B.; Conroy, M.J.; Lysaght, J. Targeting T Cell Immunometabolism for Cancer Immunotherapy; Understanding the Impact of the Tumor Microenvironment. Front. Oncol. 2014, 4, 107. [CrossRef]

31. Dedhia, P.H.; Keeshan, K.; Uljon, S.; Xu, L.; Vega, M.E.; Shestova, O.; Zaks-Zilberman, M.; Romany, C.; Blacklow, S.C.; Pear, W.S. Differential ability of Tribbles family members to promote degradation of $\mathrm{C} / \mathrm{EBP} \alpha$ and induce acute myelogenous leukemia. Blood 2010, 116, 1321-1328. [CrossRef]

32. Miyajima, C.; Itoh, Y.; Inoue, Y.; Hayashi, H. Positive Regulation of Interleukin-2 Expression by a Pseudokinase, Tribbles 1, in Activated T Cells. Biol. Pharm. Bull. 2015, 38, 1126-1133. [CrossRef]

33. Wilkin, F.; Savonet, V.; Radulescu, A.; Petermans, J.; Dumont, J.E.; Maenhaut, C. Identification and Characterization of Novel Genes Modulated in the Thyroid of Dogs Treated with Methimazole and Propylthiouracil. J. Biol. Chem. 1996, 271, 28451-28457. [CrossRef] [PubMed]

34. Wilkin, F.; Suarez-Huerta, N.; Robaye, B.; Peetermans, J.; Libert, F.; Dumont, J.E.; Maenhaut, C. Characterization of a Phosphoprotein whose mRNA is Regulated by the Mitogenic Pathways in Dog Thyroid Cells. Eur. J. Biochem. 1997, 248, 660-668. [CrossRef] [PubMed] 
35. Bowers, A.; Scully, S.; Boylan, J.F. SKIP3, a novel Drosophila tribbles ortholog, is overexpressed in human tumors and is regulated by hypoxia. Oncogene 2003, 22, 2823-2835. [CrossRef]

36. Simonovsky, E.; Schuster, R.; Yeger-Lotem, E. Large-scale analysis of human gene expression variability associates highly variable drug targets with lower drug effectiveness and safety. Bioinformatics 2019, 35, 3028-3037. [CrossRef] [PubMed]

37. GTEx Portal. Available online: https:/ / gtexportal.org/ (accessed on 12 February 2021).

38. McCall, M.N.; Illei, P.B.; Halushka, M.K. Complex Sources of Variation in Tissue Expression Data: Analysis of the GTEx Lung Transcriptome. Am. J. Hum. Genet. 2016, 99, 624-635. [CrossRef]

39. Farahbod, M.; Pavlidis, P. Untangling the effects of cellular composition on coexpression analysis. Genome Res. 2020, 30, 849-859. [CrossRef]

40. Kim-Hellmuth, S.; Aguet, F.; Oliva, M.; Muñoz-Aguirre, M.; Kasela, S.; Wucher, V.; Castel, S.E.; Hamel, A.R.; Viñuela, A.; Roberts, A.L.; et al. Cell type-specific genetic regulation of gene expression across human tissues. Science 2020, 369, eaaz8528. [CrossRef]

41. The GTEx Consortium The GTEx Consortium atlas of genetic regulatory effects across human tissues. Science 2020, 369, 1318-1330. [CrossRef] [PubMed]

42. Salomé, M.; Hopcroft, L.; Keeshan, K. Inverse and correlative relationships between TRIBBLES genes indicate non-redundant functions during normal and malignant hemopoiesis. Exp. Hematol. 2018, 66, 63-78.e13. [CrossRef]

43. Yoshino, S.; Yokoyama, T.; Sunami, Y.; Takahara, T.; Nakamura, A.; Yamazaki, Y.; Tsutsumi, S.; Aburatani, H.; Nakamura, T. Trib1 promotes acute myeloid leukemia progression by modulating the transcriptional programs of Hoxa9. Blood 2021, 137, 75-88. [CrossRef]

44. Aznarez, I.; Nomakuchi, T.T.; Tetenbaum-Novatt, J.; Rahman, M.A.; Fregoso, O.; Rees, H.; Krainer, A.R. Mechanism of NonsenseMediated mRNA Decay Stimulation by Splicing Factor SRSF1. Cell Rep. 2018, 23, 2186-2198. [CrossRef] [PubMed]

45. Calviello, L.; Hirsekorn, A.; Ohler, U. Quantification of translation uncovers the functions of the alternative transcriptome. Nat. Struct. Mol. Biol. 2020, 27, 717-725. [CrossRef]

46. Imamachi, N.; Salam, K.A.; Suzuki, Y.; Akimitsu, N. A GC-rich sequence feature in the 3' UTR directs UPF1-dependent mRNA decay in mammalian cells. Genome Res. 2017, 27, 407-418. [CrossRef]

47. Won, J.-I.; Shin, J.; Park, S.Y.; Yoon, J.; Jeong, D.-H. Global Analysis of the Human RNA Degradome Reveals Widespread Decapped and Endonucleolytic Cleaved Transcripts. Int. J. Mol. Sci. 2020, 21, 6452. [CrossRef]

48. Wu, G.; Schmid, M.; Rib, L.; Polak, P.; Meola, N.; Sandelin, A.; Jensen, T.H. A Two-Layered Targeting Mechanism Underlies Nuclear RNA Sorting by the Human Exosome. Cell Rep. 2020, 30, 2387-2401.e5. [CrossRef]

49. Noguchi, S.; Arakawa, T.; Fukuda, S.; Furuno, M.; Hasegawa, A.; Hori, F.; Ishikawa-Kato, S.; Kaida, K.; Kaiho, A.; Kanamori-Katayama, M.; et al. FANTOM5 CAGE profiles of human and mouse samples. Sci. Data 2017, 4, 170112. [CrossRef]

50. Wade, J.; Grainger, D.C. Spurious transcription and its impact on cell function. Transcription 2018, 9, 182-189. [CrossRef]

51. Cui, B.; Eyers, P.; Dobens, L.; Tan, N.; Mace, P.; Link, W.; Kiss-Toth, E.; Keeshan, K.; Nakamura, T.; Pear, W.; et al. High-lights of the 2nd International Symposium on Tribbles and Diseases: Tribbles tremble in therapeutics for immunity, metabo-lism, fundamental cell biology and cancer. Acta Pharm. Sinica B 2019, 9, 443-454. [CrossRef]

52. Murphy, J.; Nakatani, Y.; Jamieson, S.A.; Dai, W.; Lucet, I.S.; Mace, P.D. Molecular Mechanism of CCAAT-Enhancer Binding Protein Recruitment by the TRIB1 Pseudokinase. Structure 2015, 23, 2111-2121. [CrossRef]

53. Jamieson, S.A.; Ruan, Z.; Burgess, A.E.; Curry, J.R.; McMillan, H.D.; Brewster, J.L.; Dunbier, A.K.; Axtman, A.D.; Kannan, N.; Mace, P.D. Substrate binding allosterically relieves autoinhibition of the pseudokinase TRIB1. Sci. Signal. 2018, 11, eaau0597. [CrossRef]

54. Nagy, E.; Maquat, L. A rule for termination-codon position within intron-containing genes: When nonsense affects RNA abundance. Trends Biochem. Sci. 1998, 23, 198-199. [CrossRef]

55. Kurosaki, T.; Popp, M.W.; Maquat, L.E. Quality and quantity control of gene expression by nonsense-mediated mRNA decay. Nat. Rev. Mol. Cell Biol. 2019, 20, 406-420. [CrossRef]

56. Niespolo, C.; Johnston, J.M.; Deshmukh, S.R.; Satam, S.; Shologu, Z.; Villacanas, O.; Sudbery, I.M.; Wilson, H.L.; Kiss-Toth, E. Tribbles-1 Expression and Its Function to Control Inflammatory Cytokines, Including Interleukin-8 Levels are Regulated by miRNAs in Macrophages and Prostate Cancer Cells. Front. Immunol. 2020, 11, 574046. [CrossRef]

57. Briskin, D.; Wang, P.Y.; Bartel, D.P. The biochemical basis for the cooperative action of microRNAs. Proc. Natl. Acad. Sci. USA 2020, 117, 17764-17774. [CrossRef]

58. Mashima, T.; Soma-Nagae, T.; Migita, T.; Kinoshita, R.; Iwamoto, A.; Yuasa, T.; Yonese, J.; Ishikawa, Y.; Seimiya, H. TRIB1 Supports Prostate Tumorigenesis and Tumor-Propagating Cell Survival by Regulation of Endoplasmic Reticulum Chaperone Expression. Cancer Res. 2014, 74, 4888-4897. [CrossRef]

59. Shahrouzi, P.; Astobiza, I.; Cortazar, A.; Torrano, V.; Macchia, A.; Flores, J.; Niespolo, C.; Mendizabal, I.; Caloto, R.; Ercilla, A.; et al. Genomic and Functional Regulation of TRIB1 Contributes to Prostate Cancer Pathogenesis. Cancers 2020, 12, 2593. [CrossRef]

60. E Kung, J.; Jura, N. The pseudokinase TRIB 1 toggles an intramolecular switch to regulate COP 1 nuclear export. EMBO J. 2019, 38, e99708. [CrossRef]

61. Vlietstra, R.J.; van Alewijk, D.C.; Hermans, K.G.; van Steenbrugge, G.J.; Trapman, J. Frequent inactivation of PTEN in pros-tate cancer cell lines and xenografts. Cancer Res. 1998, 58, 2720-2723.

62. Kim, H.-J.; Park, Y.I.; Dong, M.-S. Comparison of prostate cancer cell lines for androgen receptor-mediated reporter gene assays. Toxicol. In Vitro 2006, 20, 1159-1167. [CrossRef] 
63. Migliorini, D.; Bogaerts, S.; Defever, D.; Vyas, R.; Denecker, G.; Radaelli, E.; Zwolinska, A.; Depaepe, V.; Hochepied, T.; Skarnes, W.C.; et al. Cop1 constitutively regulates c-Jun protein stability and functions as a tumor suppressor in mice. J. Clin. Investig. 2011, 121, 1329-1343. [CrossRef] [PubMed]

64. Vitari, A.C.; Leong, K.G.; Newton, K.; Yee, C.; O’Rourke, K.; Liu, J.; Phu, L.; Vij, R.; Ferrando, R.; Couto, S.S.; et al. COP1 is a tumour suppressor that causes degradation of ETS transcription factors. Nature 2011, 474, 403-406. [CrossRef]

65. Bastola, D.R.; Pahwa, G.S.; Lin, M.-F.; Cheng, P.-W. Downregulation of PTEN/MMAC/TEP1 expression in human prostate cancer cell line DU145 by growth stimuli. Mol. Cell. Biochem. 2002, 236, 75-81. [CrossRef]

66. Minamiguchi, K.; Kawada, M.; Someno, T.; Ishizuka, M. Androgen-independent prostate cancer DU145 cells suppress androgen-dependent growth of prostate stromal cells through production of inhibitory factors for androgen responsiveness. Biochem. Biophys. Res. Commun. 2003, 306, 629-636. [CrossRef]

67. Dallavalle, C.; Albino, D.; Civenni, G.; Merulla, J.; Ostano, P.; Mello-Grand, M.; Rossi, S.; Losa, M.; D'Ambrosio, G.; Sessa, F.; et al. MicroRNA-424 impairs ubiquitination to activate STAT3 and promote prostate tumor progression. J. Clin. Investig. 2016, 126, 4585-4602. [CrossRef]

68. Skjøth, I.; Issinger, O.-G. Profiling of signaling molecules in four different human prostate carcinoma cell lines before and after induction of apoptosis. Int. J. Oncol. 2006, 28, 217-229. [CrossRef]

69. Fraser, M.; Zhao, H.; Luoto, K.R.; Lundin, C.; Coackley, C.; Chan, N.; Joshua, A.; Bismar, T.A.; Evans, A.; Helleday, T.; et al. PTEN Deletion in Prostate Cancer Cells Does Not Associate with Loss of RAD51 Function: Implications for Radiotherapy and Chemotherapy. Clin. Cancer Res. 2011, 18, 1015-1027. [CrossRef]

70. Johnston, J.M.; Angyal, A.; Bauer, R.C.; Hamby, S.; Suvarna, S.K.; Baidžajevas, K.; Hegedus, Z.; Dear, T.N.; Turner, M.; Wilson, H.L.; et al. Myeloid Tribbles 1 induces early atherosclerosis via enhanced foam cell expansion. Sci. Adv. 2019, 5, eaax9183. [CrossRef] 